\title{
Water Borne Diseases: Life Threatening Impact on Maternal Health
}

\author{
Preeti Chaudhary, Lisa Gopal, Kumud Pant, Akshara Pande
}

\begin{abstract}
Water is the most essential substance for any life on the earth but it can also be a life threatening fluid sometimes. One of the reasons of deaths in the world is due to poor quality and unhygienic water. The world health organization estimates that $80 \%$ of diseases worldwide are water borne. The presence of contaminants in water resulted adverse health effects such as gastrointestinal problems, neurological disorders, reproductive problems and pregnancy problems which ultimately comprises the health of infants, pregnant women, elder's people and those who already suffered from any disease and on medications. In this paper, we will analyze thedifferent types of water borne diseases leading to deaths. We will focus on specific maternity age group 15-49 years in India. The considered data is provided by Institute for Health Metrics and Evaluation (IHME)-2018.This analysis will help to identify the severity of hazardous disease.These investigations will be useful for the wellness of pregnant women and their fetus. This analysis suggestsdrinking water should be check regularly to know the presence of micro organisms along with other harmful toxic elements. There is a need to organize an awareness program among the pregnant women that tells about the health risk from drinking the contaminated water during pregnancy.
\end{abstract}

Keywords: Contaminated, Polluted water, Pathogens, Waterborne diseases, Health, Maternity

\section{INTRODUCTION}

For overall health, clean drinking water plays an important role. Being a universal solvent, water acts as a major source of infection. Various reasons that cause water contamination are the indiscriminate exploitation that can occur due to rain water pollution, sewage water, growing industries and increasing population that causes various infectious and noninfectious diseases in human beings [1]. According to WHO, approx 1.1 Billion people across the world population do not get safe water [2]. Contaminated water is the ultimate cause of severe water-bornedisease like Hepatitis E, Typhoid, Acute Diarrhoea, Rotavirus, Malaria, etc. These diseases are mainly spread by pathogenic organisms that are contaminated in safe water. Most common way of transmitting infection is at the time of washing, drinking, bathing, by the intake of infected food. Diarrheal diseases are the most critical examples of waterborne disease that affect pregnant ladies and children. According to WHO, 4 billion cases of diarrhoea occurs each year[2][3].

Revised Manuscript Received on April 25, 2019.

Preeti Chaudhary, Graphic Era Hill University, Dehradun, India.

Lisa Gopal1, Kumud Pant, Graphic Era Deemed to be University, Dehradun, India

Akshara Pande (Corresponding Author), Graphic Era Hill University, Dehradun, India
Emerging waterborne pathogens will be continued to be recognized as significant public health concern due to vast range of underlying driving forces. Waterborne diseases are mostly caused due to inadequate water resources. Water gets contaminated due to many reasons in the urban areas common reasons include leaky water pipe joints in areas where sewage line and water pipe pass close together. Also, waterborne diseases are caused due to drinking unhealthy water.

Hepatitis $\mathbf{E}$ is a basically a liver disease caused by the virus Hepatitis E (HEV). This infection is very common worldwide and the main disease-causing areas are that with the unsafe drinking water and the frequent water contaminated in the resource-poor areas [4].Typhoid is a bacterial infection that leads to diarrhea, vomiting and high fever. It is caused due to bacteria named Salmonella typhi. This infection is commonly passed through drinking water and contaminated food. Cholera is an dangerous diarrheal disease that is mainly spread by the infection of the bacteriaVibrio cholera. It is a severe water-borne disease which is spread by the bacteria mainly intake by consuming dirty water. If not treated on time, it can also cause death in some rare cases [8].Rotavirus is contagious and highly transmittable. It is an infection that is caused majorly in children of under the age of 5. Children experience a high fever, irritability, dehydration, abdominal pain, vomiting.Acute Diarrhea is caused by the infection in the gastrointestinal tract and the responsible microbes are virus, bacteria and parasitic organisms. It can range from mild to potentially life threatening.

\section{LITERATURE SURVEY}

Waterborne diseases arecaused by the direct drinking of contaminated water in the presence of toxic elements and harmful microorganisms. Polluted drinking water if used for thepreaparation of food will become the cause of food borne disease by the consumption of same pathogenic microorganisms. Many waterborne diseases are classified by Diarrhoea and Typhoid, which involves excessive stooling, which results to illness and possibly death. As per WHO, diarrhea disease itself recorded for an estimated $4.5 \%$ of the daily GBD which is responsible for the deaths of 1.8 million people every year. Further analysis suggest that $88 \%$ of that ratio is subjected to unsafe water supply, sanitation and hygiene and is mostly concentrated on pregnant women and children less than 5 year old in developing countries [5] Most waterborne diseases are normally spread by the fecal transmission route, and this occurs when human fecal material is ingested by drinking polluted water or eating unhygienic food which generated from poor sewage system and improper

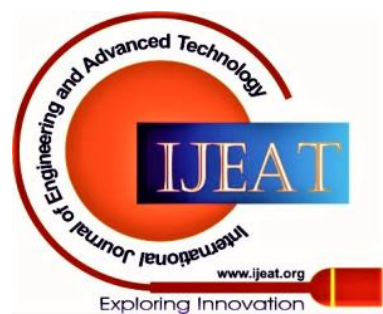


sanitation. In localities where pollution levels are low, supplies may not carry life-threatening risks. However, where pollutionlevels are high, human (especially the pregnant women, the children, the old and those suffering from immunodeficiency-related diseases) may be at a significant risk of life. Waterborne disease can be affected by viruses, protozoa, bacteria, and intestinal parasites. Some of the harmful organisms related for their role in the waterborne disease include: Diarrhoea, Cholera, Typhoid, Paratyphoid, Rotavirus, and Acute Hepatitis E.

\section{Symptoms of Waterborne Sickness:}

Most of the waterborne diseases have the common symptoms and characteristics of each symptom depend upon protozoa, viruses, bacteria and pathogenic micro organism.

1. Diarrhoea \& Gastroenteritis

2. Abdominal pain \& Cramps

3. Typhoid Fever

4. Dysentery

5. Vomiting

6. Loss of weight and fatigue may accompany several of the viral illness.

Commonly found waterborne diseases of human are represented in Table 1

Table 1.

\begin{tabular}{|c|c|c|}
\hline \multicolumn{3}{|c|}{ Common Water-Borne Diseases of Human } \\
\hline S. No & Name Of Diseases & Causative Agent \\
\hline 1 & Diarrhea & Salmonella \\
\hline 2 & Cholera & Vibrio cholera \\
\hline 3 & Rotavirus Diarrhea & Rotavirus \\
\hline 4 & Typhoid & Salmonella Typhi \\
\hline 5 & Paratyphoid & $\begin{array}{c}\text { Salmonella } \\
\text { Paratyphi }\end{array}$ \\
\hline 6 & Acute Hepatitis E & Hepatitis E Virus \\
\hline
\end{tabular}

\section{THE RECOGNIZED CHALLENGES BY THE WATER-BORNE DISEASES}

\section{Deficiency of the drinking water facility}

Even though there is a water supply facility to the people in the India, mostly the people depending on the groundwater for their drinking and domestic purposes. $70 \%$ people do not like to drink the chlorinated water due to the smell (chlorinated-odor). Because they do not habituate to the taste of the pipe-borne water supply and also the frequently cut to water supply will trigger the people to prefer the well water.

\section{Improper drainage system}

The drainage system is in poor management. The storm water kept in the small ponds and this leads to the mosquito breeding. Mosquito-borne diseases such as dengue spread due to this drainage system. In recent past, the spread and consequence of the dengue was very worst. Many deaths have registered in the regional hospitals. Many places in the coastal areas faces dengue breeding problems without the proper drainage management. Some people do not have awareness about the seriousness of the places which are prone to mosquito breeding.

\section{Scarcity of sanitation}

In the coastal area, people use water mostly from the natural sources such as groundwater, and surface water. The pots and other utensils to carry water are not hygiene and safe that some time it causes to transfer the pathogenic microorganism from one place to another. For the domestic purposes water is used carrying streams and rivers. The microbial pathogens, causes water-borne diseases spread by this activity. The dump and wastage from human and animals also causes the fecal contamination in the water.

\section{Limited resources to health Services}

Lack of health care and absence of proper health management resulted to an increased unhealthy life to the people in the coastal area. During the disaster periods, people face health challenges. Tsunami and flood have caused many health challenges in the coastal area people. The remote area people do not consider about the waterborne diseases, this leads to the chronic condition and sometime caused deaths.

\section{Scarcity of hygiene water, poor hygiene practices and bad sanitation.}

Crisis for the clean water is a major challenge to people in the disaster period namely, tsunami, drought and flood. Drought triggers the people to consume the water without considering the hygiene. During the flooding period, groundwater sources in the study area affected heavily, due to the fact that people get infected to the water-borne diseases. Cholera and diarrhea are very commonplace during the flooding time.

\section{Lack of awareness among the people}

Dearth of awareness among peoples is a greater challenge than other. Because normally people consume water for drinking and domestic purposes from unsafe sources. The agents to cause the water-borne diseases such as the wastages and sewerage water mix with drinking water sources. In many areas, people consume water only considering the appearance but not to the cleanness. Some people drink water from the streams in the paddy land, this is a major factor to cause the water-borne diseases.

\section{DATA EXPLORATION}

Over the years from 2007 to 2017, the averaged number of deaths in the maternal age group (15-49 years) caused by water borne diseases- Diarrhea, Cholera, Rotavirus, Acute hepatitis $\mathrm{E}$ and Typhoid presented in table 1, latest by Institute for Health metrics and Evaluation(IHME)-2018 [8].Diarrhea remained the leading killer of all the deaths followed by Typhoid, Acute Hepatitis E, Rotavirus and Cholera. Here we are doing analysis on each respective disease over the period gap of 2 years from 2007-2017.

\section{Results}

This Study related to risk factor and a disease provide an overall analysis of the burden of waterborne diseases specifically in India and also accounted cases, deaths, and etiologies in 2007-2017 and assesses how the effects of

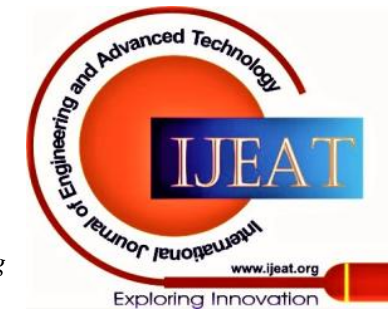


diarrhoea, cholera, rotavirus, hepatitis E and Typhoid has changed in people of all ages [6].

In the analysis we are plotting a data between the maternity age group (15-49 years) and Number of deaths (Per Million) due the following water borne diseases: Diarrhoea, Cholera, Rotavirus, Acute Hepatitis E, and Typhoid\& Paratyphoid in every two years gap from 2007 to 2017. Finally a collective summarized analysis done that depicts the averaged death rates over a decade.

In below figures $\mathrm{Y} 1, \mathrm{Y} 2, \mathrm{Y} 3, \mathrm{Y} 4, \mathrm{Y} 5, \mathrm{Y} 6$ \& $\mathrm{Y} 7$ denotes the selected ranges from 15 to 19 year, 20 to 24 year, 25 to 29 year, 30 to 34 year, 35 to 39 year, 40 to 44 and 45 to 49 year respectively.

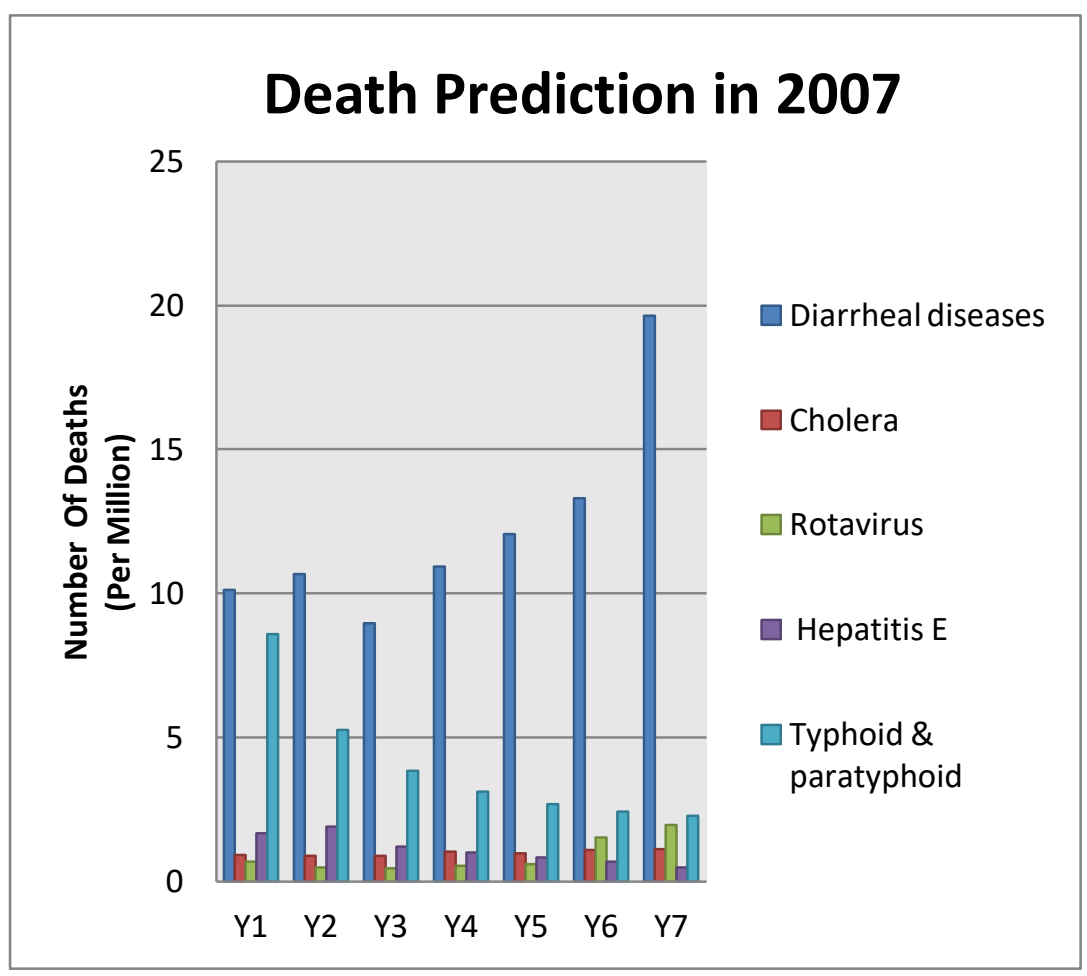

Figure 1

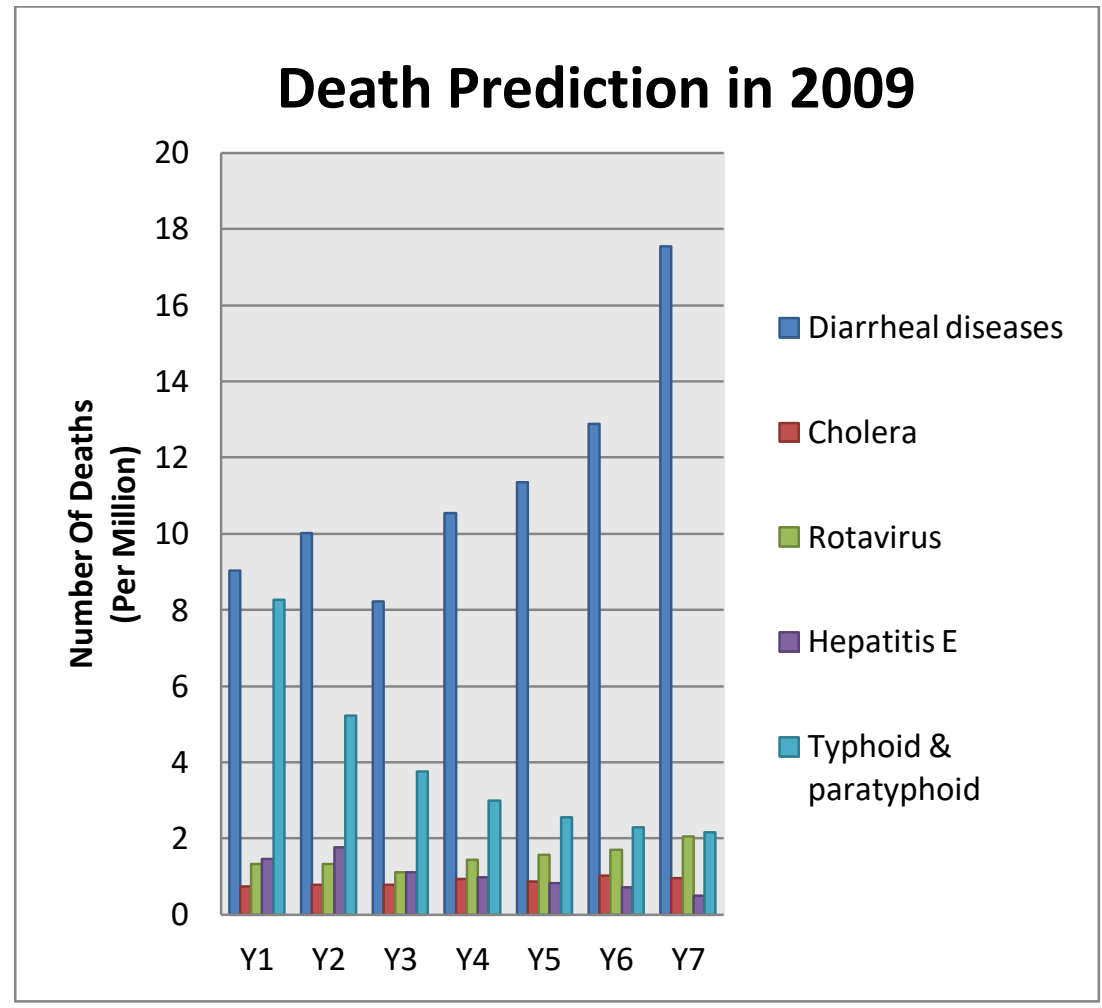

Figure 2

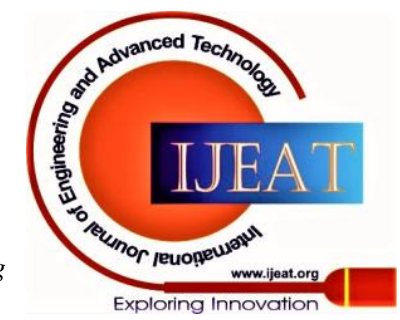




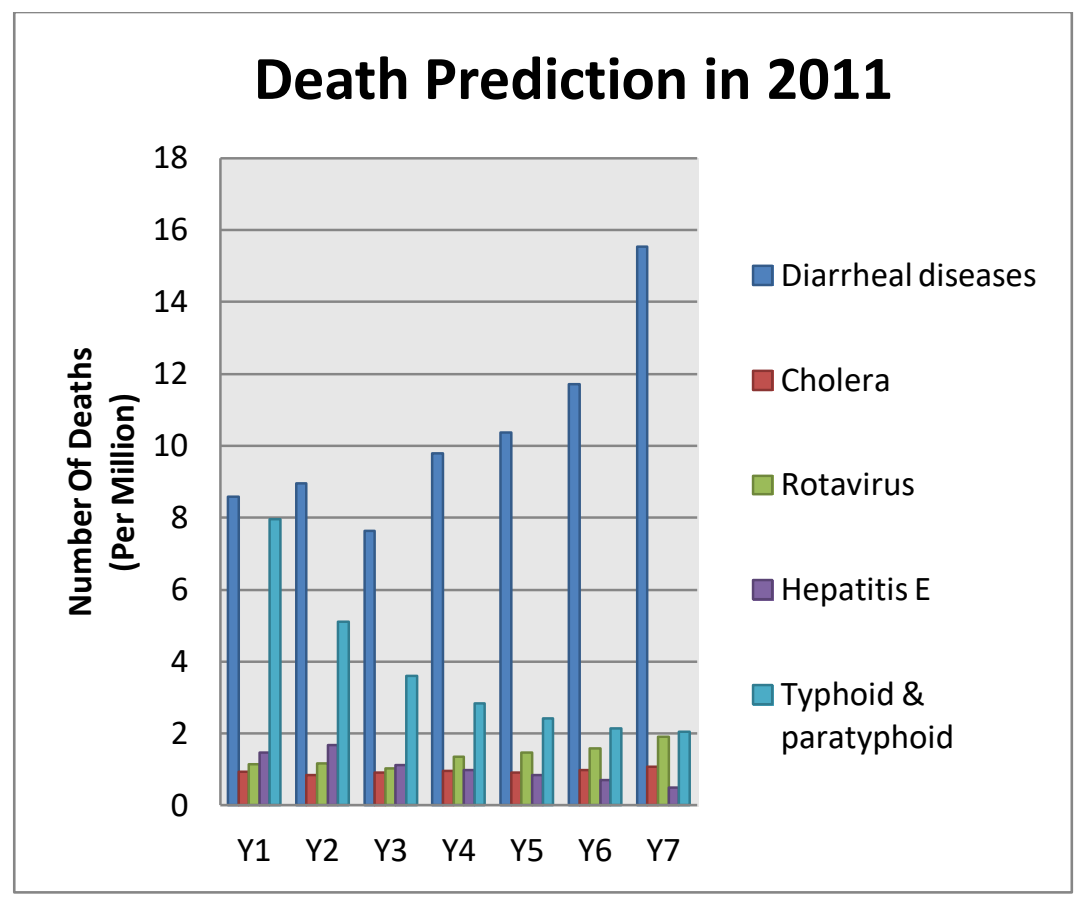

Figure 3

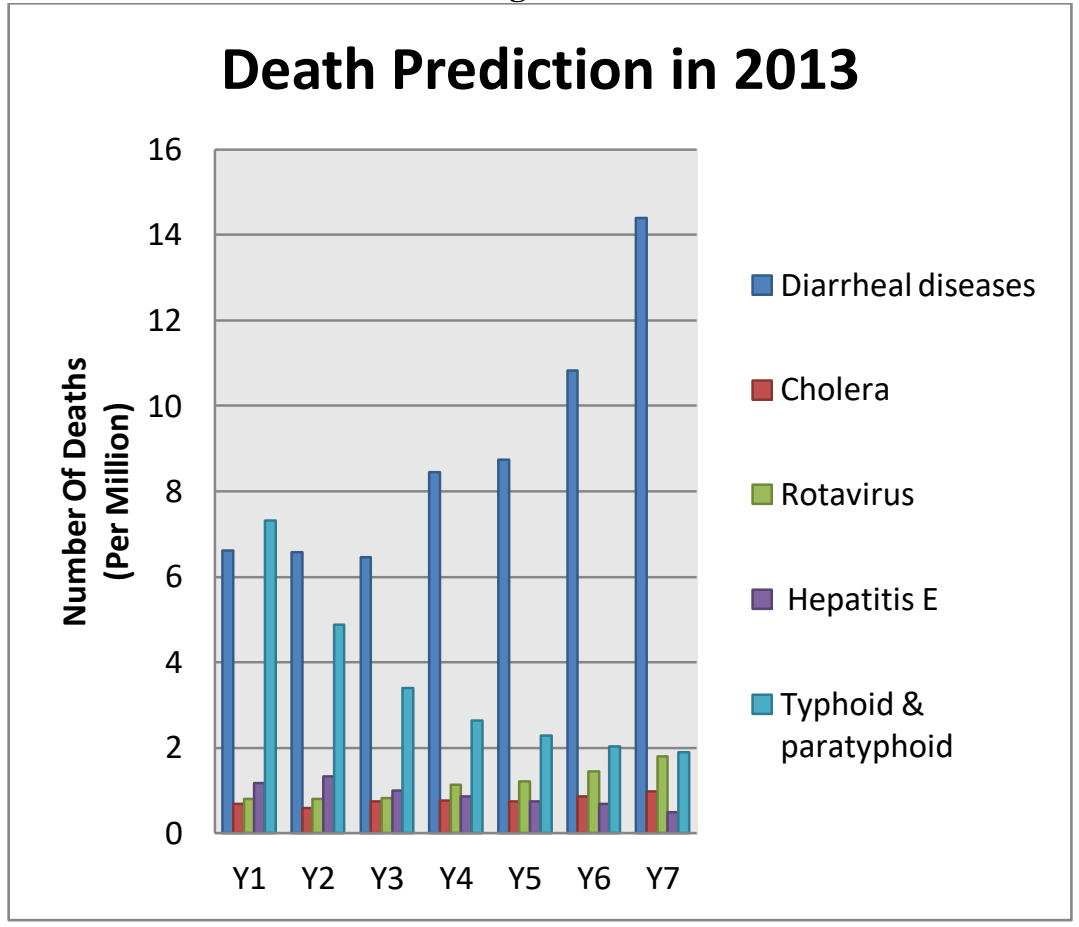

Figure 4

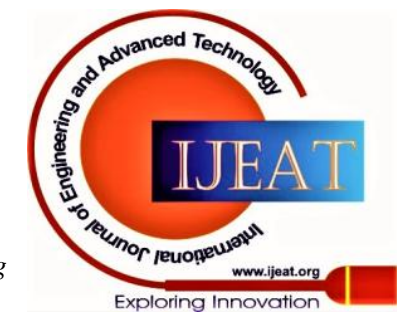




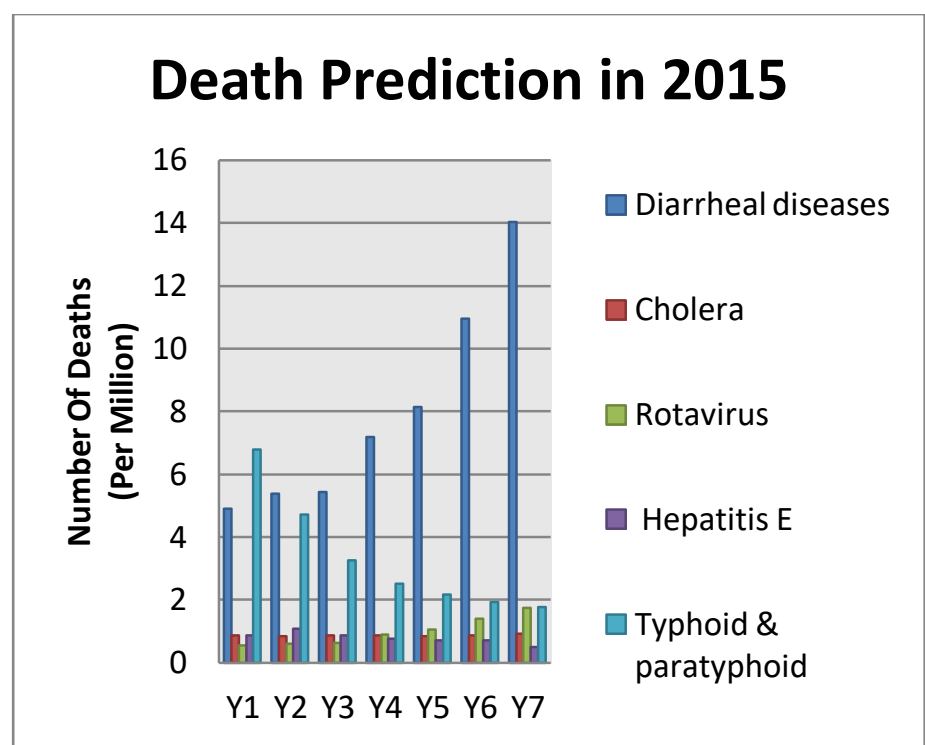

Figure 5

Table 2.

\begin{tabular}{|c|c|c|c|c|c|c|c|}
\hline \multicolumn{7}{|c|}{ Averaged Reported Deaths In The Maternal Age Group (15-49 years) By Water } \\
Borne Diseases & $\mathbf{2 0 1 1}$ & $\mathbf{2 0 1 3}$ & $\mathbf{2 0 1 5}$ & $\mathbf{2 0 1 7}$ \\
\hline S. No & Diseases & $\mathbf{2 0 0 7}$ & $\mathbf{2 0 0 9}$ & $\mathbf{2 0 1 1}$ & $\mathbf{2}$ \\
\hline 1 & $\begin{array}{c}\text { Diarrheal } \\
\text { Disease }\end{array}$ & 12.4408 & 11.3694 & 10.36892 & 8.86833 & 8.00524 & 7.90119 \\
\hline 2 & Cholera & 0.99283 & 0.87152 & 0.95014 & 0.76711 & 0.86943 & 0.85804 \\
\hline 3 & Rotavirus & 0.90049 & 1.50675 & 1.37813 & 1.14348 & 0.98262 & 0.88447 \\
\hline 4 & $\begin{array}{c}\text { Acute hepatitis } \\
\text { E }\end{array}$ & 1.11857 & 1.05608 & 1.0383 & 0.89687 & 0.78685 & 0.75835 \\
\hline 5 & $\begin{array}{c}\text { Typhoid and } \\
\text { paratyphoid }\end{array}$ & 4.02932 & 3.88859 & 3.731867 & 3.49075 & 3.31146 & 3.11924 \\
\hline
\end{tabular}

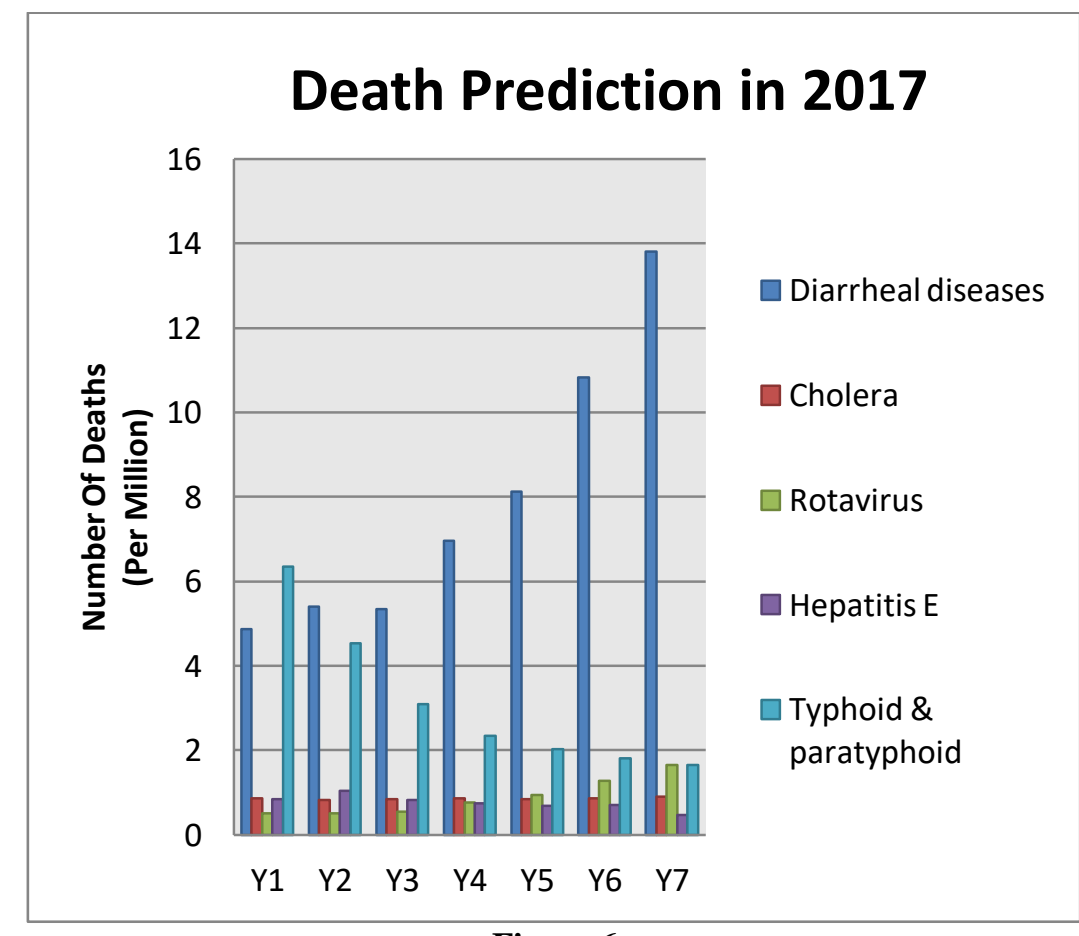

Figure 6 


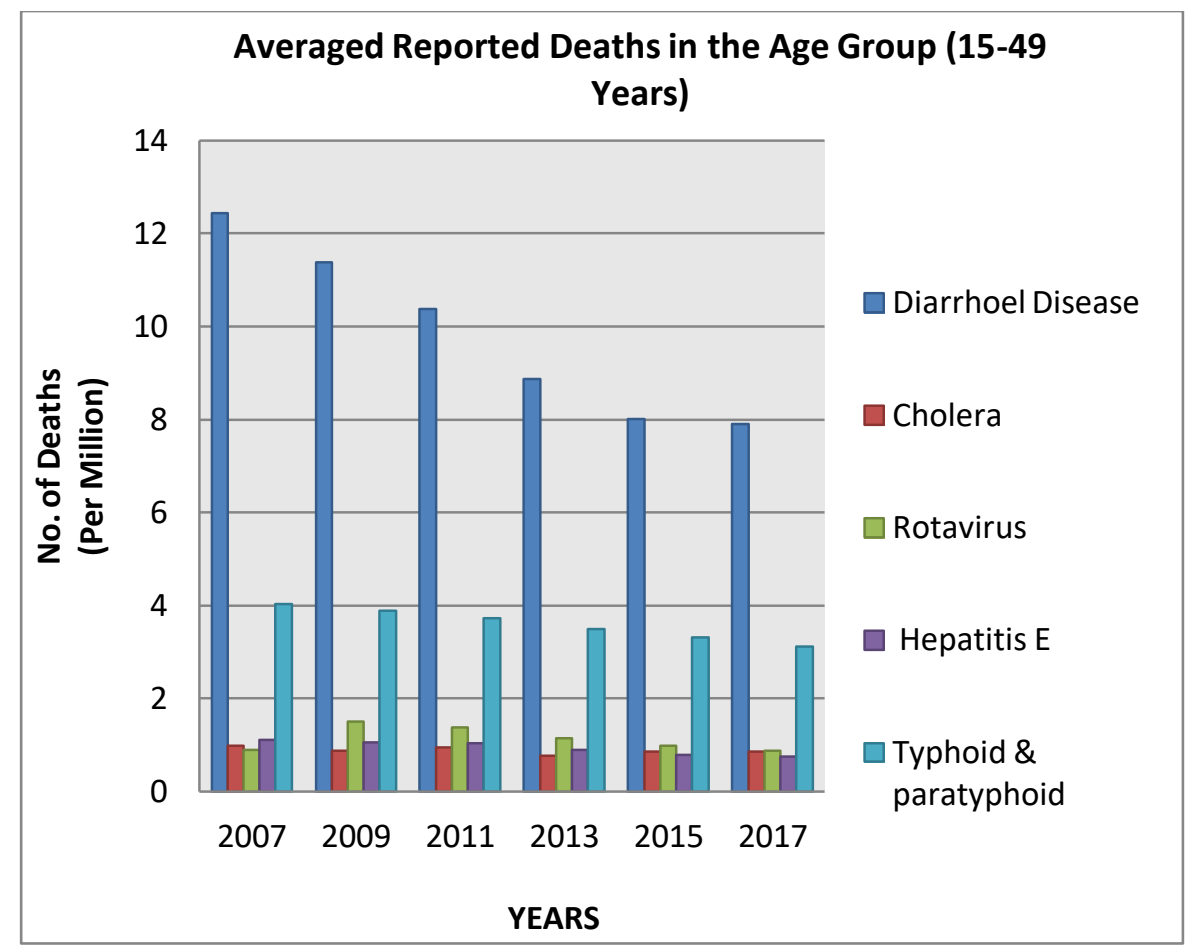

Figure 7

Our results clearly suggest that among the following Water borne Diseases, Diarrheal disease found the main leading reason of death in the specific maternity age group (15-49 years) and this is also main reason of death among children younger than 5 years due to contaminated water.

\section{CONCLUSION}

This Paper indicates the linkage between intake of polluted unsafe water and high risk of life during the pregnancy. In the presence of multiple contaminants it is very challenging to identify which contaminants and toxic elements in the drinking water system is mainly harmful for the pregnancy. Our results focused on Water Borne Disease which reflects that Diarrhea is one of the leading killer disease due to which high risk pregnancy occurs. Future studies will be in the direction of individual exposure of every contaminant in both the rural and urban areas. Survey will be done to collect information about the every reason toward a particular contaminant particularly during pregnancy. There is a need to prepare a repository for children born with such kind of defects, and a proper investigation should be done on the water supply system on a regular basis. Sources of water in the society should be regularly examined to check the level of heavy metals and the presence of microorganisms. Finally, there is also a need to conduct an awareness programs on a regular basis to prevent from the severe water-borne diseases among pregnant women in rural areas, wherein education and lack of knowledge are a prime concern.

\section{REFERENCES}

1. Ashraf, M. A., Maah, M. J., Yusoff, I. \& Mehmood, K. (2010) Effects of Polluted Water Irrigation on Environment and Health of People in Jamber, District Kasur, Pakistan,International Journal of Basic \& AppliedSciences, 10(3), pp. 37-57

2. European Public Health Alliance, (2009). Air, WaterPollution and Health Effects.
3. World Health Organization (WHO), (2010b). The World Health Report - Health Systems Financing: The Path to Universal Coverage.

4. Aggarwal, R. (2010). The global prevalence of hepatitis E virus infection and susceptibility: A systematicreview. Geneva, Switzerland: World Health Organization.

5. WHO/UNICEF. Global Water supply andsanitation assessment report. Geneva and New York: WHO and UNICEF; 2012.

6. Estimates of global, regional, and national morbidity, mortality, and etiologies of diarrheal diseases: a systematic analysis for the Global Burden of Disease Study 2017.

7. Cholera Annual Report 2017 Weekly Epidemiological Record 21 September 2018, Vol 93, 38 (pp 489-500).

8. Brijesh C. Purohit, Health Impact of Water Borne Diseases and Regional Disparities in India, International Journal of Health Sciences \& Research (2012). 